\title{
Critical Issues in Child Sexual Abuse
}

\author{
Shorouq Motwani ${ }^{1}$, Avinash De Sousa ${ }^{2}$ \\ ${ }^{1}$ Specialty Medical Officer, Department of Psychiatry, Lokmanya Tilak Municipal Medical \\ College, Mumbai, \\ ${ }^{2}$ Consultant Psychiatrist and Research Associate, Department of Psychiatry, Lokmanya Tilak \\ Municipal Medical College, Mumbai.
}

Corresponding Author: Shorouq Motwani

E-mail: shorouqmotwani@gmail.com

Child sexual abuse is an extremely important, yet underreported and inadequately acknowledged problem in today's world. That this is a colossal problem not only in the developed world, but also in underdeveloped and developing nations of the world, cannot be overstated. It also contributes to significant medical and psychological morbidity in the victims, who are innocent children and find it difficult to process the abuse that they are going through [1]. Here we will review the scope of the problem, causes, effects, symptoms, medical and psychiatric problems and approach to the solution of this massive problem.

It is paramount to understand that this problem is underreported in both Western and developing nations. Why is this so? For one, victims of sexual abuse find it very difficult to admit to their friends or relatives or even therapist that they have suffered from sexual abuse. This is because the victims feel that they are responsible for the trauma they have undergone, and sometimes feel that they have invited and attracted the abuse [2]. In our country, there is this ill-founded belief that victims of rape and sexual assault are the ones who are asking for it, because of their behavior, clothing etc. This utterly backward and sick thought process puts additional stress and trauma on rape victims and hence they do not admit what has happened to anyone.

The second point is that children sometimes do not fully understand what is happening to them. Young children are not fully cognizant of what sex and sexuality means, what is the importance of consent, and how physical and sexual attraction and intimacy are linked to feelings of love, trust and connection. At the same time, it does not require knowledge or wisdom to understand that their freedom and their bodies have been violated without their consent because of the criminal mind of someone else. So, emotionally the children are in a very confusing position of feeling cheated and betrayed yet not fully understand why this feeling has arisen [3]. Moreover, they are not able to express this to their caregivers, and the trauma gets internalized. This is the worst thing that can happen because over the course of time the internalized trauma manifests as diseases of the mind and the body.

Another important reason for sexual abuse of children is the fact that they are vulnerable, both physically and mentally. A woman in her twenties will not get into a room with an unknown person or even with a known person if she feels that something is off, but children and innocent and trust everybody. It is only after the act that the horrendous nature of the assailant's plan becomes obvious to them, and sometimes even then it may not! [4].

Then there is the bigger and more real issue- even if a child who has been sexually abused reports it to his parents, quite often the parents brush it under the carpet and behave as though it never happened. Again, these are linked to so called societal values of honour and standing of the family. There is the pervading belief that hiding an episode of rape is better than reporting it (even if it brings justice, closure and treatment of the child) and dealing with 'loss of honour of the family' or 'inability of the child to get married in the future'. When this happens, the victim does not get the medical and psychiatric treatment that he or she needs. On top of this, the parents' refusal to even acknowledge the crime mentally devastates the child and puts him (or her) into a never ending 
spiral of guilt, depression, hopelessness, failure and persistent attraction of abusive partners and spouses.

One more cause for the improper handling of this problem is the lack of initiative and apathy shown by the authorities towards victims of sexual abuse and their families. The police mistreat and make fun of these victims and try to dissuade them from making police reports and court cases, again citing the excuse of honour of the family and unwanted media attention. The legal system in this nation is also broken. By the time the case reaches the courts and a verdict can be delivered, years or even decades pass. Moreover, rich and influential people are able to bribe police officers and judges to make sure there is never a case, or even if there is, that there is never a verdict against them [5].

Bonds between parents and children are not always the best. Effective communication is often absent between parents and children. Children are not comfortable discussing even routine issues like school and friends with their parents, so something like sexual abuse is really out of the question. There is also some element of fear in the parent child relationship. The child feels that if he says such things like sexual assault, the parents will physically beat him or throw him out of the house. So, it is easy to understand why the child prefers to keep quiet rather than tell the parent what has happened.

Another important issue is that men (and even women) are not taught from a young age that women should be respected, and children are angels of God and should be given only love and positivity. They believe women and children are easy targets for sex. Since they are physically weaker, they cannot even resist. It is the responsibility of every parent to raise a child with the values of respecting women and children, honouring consent and never forcing anyone to do anything against their will.

A major factor which facilitates the abuse and also impedes the early reporting of such abuse is the fact that in most cases, the accused is someone known to the victim. More often than not, it is usually the father, uncle or in most cases a figure with whom the child is generally comfortable and thus can be easily persuaded to give in to such ghastly acts.

The issue of children being used for sex trafficking in many parts of the world is huge. Street children, school dropouts, children from poor families and children who run away from homes are prime targets for sex traffickers. Once into the system, it becomes almost impossible to get out of it. Many times, the police and politicians are also involved with these criminals in order to satisfy their financial desires. In the bargain, the children's lives get devastated [6].

The impact sexual abuse has on children can never be overstated enough. They are physically and mentally broken and become a shadow of their former selves or potential future selves. Depression is probably the most common effect of being a victim of this horrendous and sick crime. The child loses interest in life and comes to believe that there is no meaning in life. Their strong belief in God or a creator is lost. After all, which God would create humans who rape and torture innocent children? Suicide is an eventuality that must be considered in every such case [7].

Anxiety is another common complication. There are continuous feelings of anxiety, restlessness and nervousness. There is constant replaying of the traumatic experience in the mind which causes sympathetic over-activation, inability to sleep and again, a suicidal tendency. Psychotic behaviour consisting of illusions, delusions and hallucinations can also occur. A sexual abuse event can be a trigger for the development of schizophrenia. The onset of depression, anxiety disorder and psychotic disorder is fertile ground for the development of substance abuse. Moreover, substance abuse can be a form of escape from the reality of being a sexual abuse victim. A number of cases suffering from conversion disorder and psychogenic non epileptic seizures have also been diagnosed in children who have been sexually abused [8].

Children also face abandonment abuse from their families. They lose trust in their parents and distance themselves from them. It is also quite common for such children to leave their homes and completely cut off ties with the family. They become lonely and unhappy souls, always irritable and on the verge of suicide. It also becomes extremely difficult for them to form intimate relationships in the future. They bring patterns of guilt and victimhood into every relationship, constantly fearing that they will be abandoned, hurt and abused by their partners. Many of these children also enter the world of crime, becoming murderers, thieves, rapists and drug distributors. 
They may also sexually abuse another person in the future as a form of revenge and hence this vicious cycle continues. It becomes extremely difficult to stop such cycles unless drastic interventions are done.

Such victims of sexual abuse are often reluctant to procreate and have children because they feel their children can also become victims of sexual abuse. There are also medical issues at stake here. Sexually transmitted infections (STIs) are common when sexual abuse occurs. HIV is likely to be transmitted to recipients of sexual intercourse rather than the active partner. Also there is spread of other STIs like syphilis, gonorrhea, herpes etc. There can also be trauma to the genital tract in forced abuse, leading to tears, fistulae with the urinary or gastrointestinal tracts or even gastrointestinal perforation. Any of these conditions can lead to death. Another worrisome issue is that of childhood or teenage pregnancy which can be a grave result of the sexual abusive act. Realizing that the child is pregnant as a result of abuse can have devastating effects on the child who might not be able to grasp the gravity of the situation and also on the parents of such child who would now have to manage not only the fragile mental state but also the unwanted pregnancy [9].

When such victims of sexual abuse suffer from a psychiatric disorder, their general health and nutrition suffers. Hence, they are prone to develop malnutrition, vitamin and mineral deficiencies and diseases like tuberculosis. Human Papillomavirus infection, if transmitted during sexual intercourse, can lead to malignancies of the cervix, vulva, vagina and anus.

It is also well known that memories of traumatic diseases are stored in the cells. When intense emotional trauma occurs, there are also epigenetic changes in the cells like DNA methylation and histone acetylation and de-acetylation. This leads to changes in the pattern of gene expression which can lead to weakening of the immune system and susceptibility to infections. It also has been purported to have a role in the development of hypertension, diabetes mellitus, autoimmune diseases and cancer [10].

What can we do to address the humungous problem of child sexual abuse and its attendant consequences? For one, there should be awareness of this problem even in the remote rural areas. Government and voluntary organizations should take efforts to educate the people about the existence of this problem. It should be introduced into the curriculum of schools so that children are aware of this problem from an early age and are able to recognize it when it happens to them or to their peers.

It is important to have grassroots level health workers at every Primary Health Centre who can be approached about this problem, and who can coordinate with higher medical services and also with police and legal authorities. The police and courts should be made more efficient and sexual abuse cases should be made a priority. They should be processed in Fast Track Courts and verdicts should be given as soon as possible. Sentences for rapists should be extremely strict. The identity of the victim should be kept hidden as much as possible from the press.

It is important to inculcate into people that children and women should be respected and treated as equals. Rapists should be looked upon with disdain and reported to the pol ice, rather than protected.

Psychiatric help is essential for the proper management of victims of sexual abuse. It is important for them to have a therapist with whom they can talk, express their feelings and emotions, and achieve catharsis. Drug therapy also has a role in the treatment of depression, anxiety and psychotic disorders. It is also important for the patients and their families to continuously follow up and be in touch with the system. Failure of follow up can lead to relapse. It is also important to have a team of social workers at every level who can help both the patient and the family with the consequences of sexual abuse. They will help the patient to get a job, earn money and become independent. They will also help the family to slowly integrate itself to the society without feelings of guilt or remorse [11].

There should be proper legislation which is very clear and explicit to deal with matters of sexual abuse. There should be a positive expression of such issues in the media, newspapers, films and movies. These can be a source of empowerment for victims of sexual abuse and marginalized groups. If the courts can convict high ranking officials and rich people who are guilty of rape rather 
than protecting them, it will set an example and infuse life into this country and the world, giving it hope that we can finally overcome the problem of child sexual abuse.

\section{REFERENCES}

1. Murray LK, Nguyen A, Cohen JA. Child sexual abuse. Child Adolesc Psychiatr Clin 2014;23(2):321-37.

2. Crosswhite JM, Kerpelman JL. Coercion theory, self-control, and social information processing: Understanding potential mediators for how parents influence deviant behaviors. Deviant Behav 2009;30(7):611-46.

3. Blakemore T, Herbert JL, Arney F, Parkinson S. The impacts of institutional child sexual abuse: A rapid review of the evidence. Child Abuse Negl 2017;74:35-48.

4. Sanjeevi J, Houlihan D, Bergstrom KA, Langley MM, Judkins J. A review of child sexual abuse: Impact, risk, and resilience in the context of culture. J Child Sex Abuse 2018;27(6):622-41.

5. Mathews B, Collin-Vézina D. Child sexual abuse: Toward a conceptual model and definition. Trauma Viol Abuse 2019;20(2):131-48.

6. Browne-James L, Litam SDA, McRae L. Child Sex Trafficking: Strategies for Identification, Counseling, and Advocacy. Int J Adv Couns 2021;43(2):113-25.

7. Douglas M, Schatte D, Harper RA. The Aftermath of Childhood Sexual Abuse: A Case Report and Review of the Literature. Adolesc Psychiatry (Hilversum) 2011;1(3).

8. Vincentiis S, Valente KD, Thomé-Souza S, Kuczinsky E, Fiore LA, Negrao N. Risk factors for psychogenic nonepileptic seizures in children and adolescents with epilepsy. Epilepsy Behav 2006;8(1):294-8.

9. Fortin-Langelier E, Daigneault I, Achim J, Vézina-Gagnon P, Guérin V, Frappier JY. A Matched Cohort Study of the Association Between Childhood Sexual Abuse and Teenage Pregnancy. J Adolesc Health 2019;65(3):384-9.

10. Hindin P, Btoush R, Brown DR, Munet-Vilaro F. Intimate partner violence and risk for cervical cancer. J Family Viol 2015;30(8):1031-43.

11. Sawrikar P, Katz I. Barriers to disclosing child sexual abuse (CSA) in ethnic minority communities: A review of the literature and implications for practice in Australia. Children Youth Serv Rev 2017;83:302-15.

Acknowledgements: Nil

Funding: Nil

Conflict of interest: Nil 